\title{
ENGEVISTA
}

Página da revista: http://www.uff.br/engevista/seer/

\section{Diagnóstico estratégico de propriedades agrícolas familiares: estudo de casos em Oriximiná (Pará)}

\section{The rural family farms strategy diagnostic: case study in Oriximiná (Pará)}

\author{
Kayo Vinicius Machado Romay ${ }^{1}$ \\ José Carneiro Viana Júnior ${ }^{2}$ \\ Leonardo da Silva Hamacher ${ }^{3}$ \\ Marcelo de Lima Souza ${ }^{4}$ \\ Dirlane de Fátima Carmo 5
}

Resumo: Neste trabalho buscou-se avaliar a viabilidade da utilização do diagnóstico por meio de matriz estratégica como uma ferramenta que auxiliasse a identificar alternativas para o desenvolvimento local de uma atividade. $\mathrm{O}$ trabalho foi realizado em propriedades de agricultores familiares que comercializavam olerícolas em Oriximiná (Pará), sendo selecionados pelo método não-probabilístico de amostragem por julgamento. Os dados foram obtidos em campo por meio de entrevista, sendo montada matrizes SWOT que foram compiladas em uma matriz de análise estratégica apontando o potencial ofensivo e defensivo e a vulnerabilidade e debilidade dos empreendimentos perante a si mesmos e ao mercado. Pelo potencial ofensivo encontrado verificou-se que a atividade agrícola nestas propriedades é promissora, alcançando um valor em torno de $77 \%$ do potencial máximo, destacando-se a oferta de produtos diversificados e a adoção da tecnologia PAIS (Produção Agroecológica Integrada Sustentável). As debilidades no sistema que devem ser foco de estratégias são o investimento do poder público em assistência técnica para capacitar os produtores a utilizarem equipamentos e adotarem manejo adequado, seja para adaptação às dificuldades impostas pelo clima ou para agregar valor, bem como atender à legislação ambiental, permitindo maior retorno do investimento.

\footnotetext{
${ }^{1}$ UFF - Universidade Federal Fluminense

${ }^{2}$ UFF - Universidade Federal Fluminense

${ }^{3}$ UFF - Universidade Federal Fluminense

${ }^{4}$ UFF - Universidade Federal Fluminense

${ }^{5}$ UFF - Universidade Federal Fluminense
} 
Palavras-chave: Agricultura familiar, diagnóstico estratégico, Amazônia, SWOT.

\begin{abstract}
This work aimed to evaluate the feasibility of using the diagnosis through strategic matrix as a tool that would help to identify alternatives for local development of an activity. The work was carried out on properties of farmers who traded vegetable crops in Oriximiná (Pará) and selected by non-probabilistic method of sampling for trial. The data were obtained by the interview generating a matrix of SWOT (Strengths, Weaknesses, Opportunities and Threats) analysis. By the good potential found it was verified that the agricultural activity in these area is promising. reaching a value around $77 \%$ on the maximum potential, highlighting the offering of diversified products and the adoption of the SIAP (Sustainable Integrated Agroecological Production) technology. However, there are deficiencies on the system which should be the main goal of the strategies such as the necessity of the public authorities action investing on the technical assistance, in order to be able to improve the quality of the producer in using equipments and also to adopt the adequate handling, which is for the adaptation to imposed obstacle by the climate or for aggregating value as well as to attend the environmental law, allowing major investment feedback.
\end{abstract}

Keywords: Family farmers, strategic diagnosis, Amazonia, SWOT. 


\section{Introdução}

A agricultura satisfez uma demanda crescente de alimentos durante a última metade do século XX devido principalmente a avanços científicos e inovações tecnológicas, tais como o desenvolvimento de novas variedades de plantas, o uso de fertilizantes e agrotóxicos e o crescimento de infraestrutura para irrigação (GLIESSMAN, 2005). Entretanto, as técnicas, inovações, práticas e políticas que permitiram aumentar o sistema de produção global de alimentos também minaram sua base, pela extração excessiva dos recursos naturais e sua degradação, pela dependência criada a materiais não renováveis como os combustíveis fósseis, por não considerarem a dinâmica ecológica dos agroecossistemas, por enfraquecerem e desmantelarem as condições sociais que conduzem à conservação de recursos (GLIESSMAN, 2005). Portanto, a agricultura moderna levou paulatinamente à descapitalização de agricultores, principalmente os familiares, e a uma consequente migração rural-urbana.

Entretanto, nas últimas décadas no Brasil este movimento migratório vem se reduzindo, visto que ocorreu no final do século passado o agravamento da crise metropolitana, alimentada pelo aumento da população urbana e a falta de oportunidades, fazendo com que aumentasse o desemprego, a pobreza, a informalidade e a violência nas grandes cidades (NERI, MELO e MONTE, 2012). Além disso, o governo federal tem investido em políticas públicas que favorecem o meio rural, tais como o programa bolsa família, facilidade ao crédito com o Programa Nacional de Fortalecimento da Agricultura Familiar (PRONAF), bem como tem aumentado os incentivos à assistência técnica, haja vista a instituição da Política Nacional de Assistência Técnica e Extensão Rural (PNATER) em 2010 (BRASIL, 2012).

Deve-se ressaltar que a agricultura familiar representa um importante setor da economia, sendo um pilar para a produção de alimentos e para o desenvolvimento do país (MACEDO e BORTOT, 2011). Apesar de a agricultura familiar responder por $84,4 \%$ das propriedades rurais no Brasil, a área total ocupada é de $24,3 \%$, entretanto, é a principal fornecedora, para a população brasileira, de alimentos básicos como: feijão (70\%), leite (58\%), mandioca (87\%), milho (46\%), aves (50\%) e suínos (59\%). As cadeias da agricultura familiar respondem por quase 10\% de todo o Produto Interno Bruto (PIB) brasileiro (BRASIL, 2010).

Assim, considerando a importância da agricultura no país, aumentar a produtividade sem avançar a fronteira agrícola é uma questão relevante nos aspectos econômico, social e ambiental, principalmente se forem apreciadas áreas estratégicas de floresta preservada como a Amazônica.

Como ressaltado por Metzger (2010) a extensão das áreas de reserva legal na Amazônia são altas, mas podem ser justificadas pelo princípio de precaução, dada à imensa riqueza biológica encontrada nestes sistemas, pelo conhecimento ainda restrito sobre os efeitos em longo prazo do desmatamento na Amazônia, e pelas amplas possibilidades de exploração 
sustentável de produtos florestais. Entretanto, há produtores rurais que consideram as áreas de Reserva Legal na Amazônia muito extensas e ociosas (CALDEIRA et al, 2010). Esta visão na verdade é comum a muitos produtores rurais que não utilizam o manejo sustentável.

Como bem destacado por Souza (2010) a falta de alternativas de atividades econômicas sustentáveis é que leva a população a práticas criminosas como forma de sobrevivência. Portanto, opções de exploração da floresta e de produção agrícola que estejam em consonância com o ambiente, mas que sejam ao mesmo tempo lucrativas e viáveis são imprescindíveis.

Para isso, torna-se necessário avaliar como os produtores rurais realizam suas atividades, qual a relação que têm com o meio, quais potencialidades podem ser desenvolvidas e quais pontos fracos devem ser minimizados ou eliminados visando aproximar a atividade rural local da sustentabilidade.

Assim, o objetivo desse trabalho foi avaliar o uso da análise estratégica no diagnóstico da atividade de olericultura realizada por agricultores familiares em diferentes localidades de Oriximiná (Pará). A olericultura nesse município é uma das principais atividades da agricultura familiar associada principalmente ao cultivo de mandioca e à pecuária mista, sendo considerada, entretanto de subsistência. Recentemente, os agricultores locais passaram a investir em uma produção comercial por observarem que há um mercado consumidor ávido devido à relativa expansão populacional da região provocada pela instalação de indústrias mineradoras (MIRANDA, 2012),

Assim, para o diagnóstico local, a partir de várias matrizes SWOT (Strengths, Weaknesses, Opportunities and Threats), foi construída uma Matriz Estratégica, que como ressaltado por Marcelino (2003), é um instrumento fundamental para a definição do plano de ação, visto que as oportunidades e ameaças elencadas, bem como a determinação dos traços mais característicos do empreendimento sendo cruzados resultam na aferição do potencial ofensivo e defensivo, bem como da vulnerabilidade e debilidade do empreendimento perante a si e ao mercado.

Trabalhos de caracterização da atividade rural de uma propriedade ou de uma região, visando um gerenciamento estratégico para alcançar um desenvolvimento equilibrado têm sido realizados, como os de Ferreira e Alencar (2007); Nascimento, Souza e Souza (2009), Somini et al. (2012); mas demonstram ainda a incipiência do assunto atrelada à sua importância relacionada à agricultura familiar e a necessidade de utilização de uma ferramenta que auxilie no diagnóstico.

Deve-se ressaltar que a valorização do saber dos produtores locais, nativos da região é indispensável para um planejamento rural sustentável. Ab’Saber (2010) destaca essa importância aplicada na Amazônia ao relatar casos de degradação causados por produtores rurais não ligados à área. 
Avaliar as propriedades rurais a partir da percepção dos que realizam a atividade, assume importância em qualquer região do país, principalmente em áreas onde estejam grandes florestas como a Amazônica.

\section{Metodologia}

O município de Oriximiná está localizado no oeste do estado do Pará, mais precisamente na região denominada Baixo Amazonas. Segundo dados do censo de 2010 do Instituto Brasileiro de Geografia e Estatística - IBGE (IBGE, 2012), o município de Oriximiná abrange 107.603, $292 \mathrm{Km}^{2}$ e uma população de 62.794 habitantes.

Em termos de conservação da floresta Amazônica é interessante ressaltar que Oriximiná é o segundo maior município do estado do Pará em extensão territorial. O desmatamento nessa região preocupa e a atividade agrícola é uma de suas principais causas. De acordo com o Instituto Nacional de Pesquisas Espaciais (INPE) através do Projeto de Monitoramento do Desflorestamento na Amazônia Legal (PRODES), no período de agosto de 2011 a julho de 2012 ocorreu a menor taxa anual estimada de desmatamento na Amazônia. Entretanto, dentre os nove estados que compõe a Amazônia legal, o Pará foi o que apresentou a maior taxa, 1699 quilômetros quadrados, correspondendo a aproximadamente $36 \%$ do desmatamento estimado (INPE, 2012). Souza (2010) indicou a pecuária e o avanço da fronteira agrícola, principalmente devido ao plantio da soja, como responsáveis pelo desflorestamento no Pará.

Os dados deste trabalho foram obtidos em campo por meio da observação e entrevista direcionada para atender aos objetivos da pesquisa, conduzida de forma a deixar os agricultores se expressarem, seguindo conceito indicado por Gil (2008), indagando sobre pontos chave ao mesmo tempo em que se estimulava a opinião dos agricultores sobre assuntos de interesse ao atendimento do objetivo do trabalho que auxiliariam na qualificação e ponderação da análise estratégica. Partindo-se do pressuposto do estudo que seria avaliar as propriedades agrícolas familiares que trabalhassem com olericultura, mandioca e pecuária mista, a ferramenta que se mostrou mais adequada, considerando o conceito adotado por Yin (2001), foi o estudo de casos múltiplos, considerando, portanto a lógica da replicação.

Para a seleção das propriedades utilizou-se o método não probabilístico de amostragem intencional ou por julgamento. Essa escolha foi justificada pelo caráter qualitativo do estudo ao avaliar uma atividade que apesar de ser uma das principais para a agricultura familiar, era de subsistência e apenas recentemente vem se tornando comercial (MIRANDA, 2012). Há, portanto uma dificuldade inicial para sua quantificação, o que pode ser confirmado ao avaliar os dados apresentados nos censos do IBGE, em que a olericultura não é contemplada. 
Não houve dessa forma a possibilidade de aplicação do método probabilístico para amostragem, entretanto, como ressaltado por Oliveira (2001), se for adotado um critério razoável de julgamento os resultados são favoráveis.

No intuito de atingir esse critério e escolher famílias que fossem atores chaves, considerando a atividade comercial da agricultura familiar do município, a seleção das propriedades foi feita a partir do julgamento de representatividade feito por órgãos atuantes na atividade agrícola de Oriximiná, que são: SEMAGRI (Secretaria Municipal de Agricultura e Abastecimento), inspetoria do Conselho Regional de Engenharia e Agronomia do Pará (CREAPA), SEMA (Secretaria de Meio Ambiente) e EMATER-PA (Empresa de Assistência Técnica e Extensão Rural).

Foram entrevistadas quatorze famílias de agricultores, em propriedades localizadas em três regiões de acordo com características peculiares: Terra Firme (áreas sem inundação); Várzea (áreas periodicamente inundadas) e Ribeirinha (próximas a cursos d'água).

Para interpretação dos dados obtidos e formulação de estratégias foi utilizada a análise S.W.O.T (strengths; weaknesses, opportunities, threats) em que são identificadas as forças e fraquezas da empresa e as oportunidades e ameaças em relação ao ambiente externo. A partir da análise SWOT foi montada uma matriz de análise estratégica confrontando as fraquezas e as forças com as oportunidades e ameaças, adotando-se uma pontuação de acordo com os seguintes critérios na avaliação da relação: se pouco significativa (1), se significativa (2) e se muito significativa (3), conforme Marcelino (2003). A intenção no uso dessas ferramentas é de avaliálas como metodologias passíveis de serem utilizadas em extensão rural, para o diagnóstico individual, extrapolando para diagnóstico local participativo com o uso da matriz estratégica.

As propriedades visitadas podem ser enquadradas como de agricultura familiar considerando a definição dada na lei federal no. 11326 (BRASIL, 2006) e salientando que o módulo fiscal na cidade de Oriximiná é de setenta e cinco hectares de acordo com a Instrução Especial no. 20 do Instituto Nacional de Colonização e Reforma Agrária (INCRA, 1980).

\section{Resultados e discussão}

A construção do diagnóstico estratégico da atividade agrícola familiar em Oriximiná foi feita a partir do diagnóstico externo e interno, construindo-se a matriz SWOT das propriedades analisadas. No diagnóstico externo foi considerado o município de Oriximiná e suas peculiaridades em relação aos empreendimentos agrícolas, sendo estes últimos analisados no diagnóstico interno. As análises foram baseadas na interpretação dos dados fornecidos pelos agricultores que participaram desta pesquisa e nas observações in loco. 
O diagnóstico externo permitiu a identificação das oportunidades e ameaças, considerando o macroambiente e o setor de negócios, e o diagnóstico interno por sua vez, permitiu a identificação dos pontos fortes e fracos das propriedades.

Analisando a cidade de Oriximiná como macroambiente, verificou-se que esta apresenta $31,2 \%$ da população vivendo na zona rural de acordo com o censo demográfico de 2010, correspondendo a aproximadamente 1000 propriedades. A agropecuária foi responsável por aproximadamente 6\% do Produto Interno Bruto do município no ano de 2010 (IBGE, 2012). De acordo com o IBGE (2012), as principais formas de utilização agrícola da terra são lavouras permanentes (destacando-se a banana, café e laranja), lavouras temporárias (destacando-se a cana, mandioca, milho e feijão) e a grande maioria ocupada por pastagens naturais, degradadas ou plantadas. Na pecuária, no ano de 2011 (IBGE, 2012), destacou-se a bovinocultura, com um rebanho de 125.350 cabeças. De acordo com os dados do IBGE, no ano de 2011, Oriximiná produziu 8.799 mil litros de leite, 1.410 quilos de mel e 37.000 dúzias de ovos de galinha.

Como órgãos que podem atender tecnicamente aos produtores rurais destacam-se a Unidade Avançada José Veríssimo (UAJV) da Universidade Federal Fluminense, a Empresa de Assistência Técnica e Extensão Rural (EMATER) e a Secretaria Municipal de Agricultura e Abastecimento (SEMAGRI).

Considerando o escoamento da produção, bem como a locomoção de moradores do interior para os bairros centrais, deve-se ressaltar que o município é carente em transporte público, sendo comum a utilização de serviços de moto-taxi e hidrovias. A malha rodoviária é composta de poucas rodovias, sendo o principal acesso pela estrada estadual PA-254. A estrada é parcialmente pavimentada até o quilômetro oito onde dá acesso ao Aeroporto Municipal Brigadeiro Cantídio Bentes Guimarães, sendo que a partir deste ponto as condições se tornam precárias (MS/UFPA, 2009). Deve-se ressaltar que uma das grandes dificuldades encontrada para a realização deste estudo foi em relação ao transporte, visto que algumas propriedades só puderam ser visitadas pela utilização de voadeiras (tipo de lancha).

A produção agrícola do município é destinada à feira que também é abastecida por produtos cultivados na cidade Santarém.

A cidade de Oriximiná encontra-se dentro do bioma amazônico, sendo nela encontradas matas de terra firme; de Várzea, de Igapó e Ribeirinhas.

As matas de terra firme são áreas altas, distantes dos rios e sujeitas a alteração, também conhecidas na região como planalto. Foi verificado durante as visitas que as áreas ocupadas por estas matas eram as mais utilizadas pelas propriedades agrícolas ao redor do perímetro urbano.

As áreas de Várzea por sua vez são periodicamente inundadas pelas cheias dos rios. Apesar do terreno alagar por vários meses do ano, é a região com maior desenvolvimento agrícola familiar, sendo comum a adoção de um sistema de cultivo protegido suspenso, que 
permite a produção durante as épocas de cheia. De acordo com Miranda (2012), o cultivo de olerícolas tem maior incidência nas várzeas por questões culturais.

As matas de Iguapó também são conhecidas na região como Igarapé, mesmo não constituindo um curso d'água e situam-se em áreas baixas, próximas ao leito dos rios, permanecendo inundadas durante quase o ano todo. Não foi constatado o aproveitamento agrícola em áreas de Iguapós.

Verificou-se que havia áreas que não se enquadravam nas características de Terra firme por estarem próximas a cursos d'água, diferindo também das Matas de Iguapó por não serem alagáveis, sendo chamadas de Ribeirinhas.

Portanto, para elaboração do diagnóstico estratégico e comparação das peculiaridades das atividades agrícolas realizadas pela agricultura familiar, foram levantadas características básicas de algumas propriedades em três regiões distintas de Oriximiná: Terra Firme, Várzeas e Ribeirinhas. Deve-se ressaltar que as entrevistas foram feitas com os produtores rurais, responsáveis pelas propriedades agrícolas visitadas.

\section{a) Terra Firme:}

Nesta região foram visitadas duas propriedades.

A primeira possuía uma área de cem hectares e obtinha a maior parte da renda da produção de hortaliças, mas com pretensões de maiores investimentos no manejo de gado.

O produtor optou pelo cultivo suspenso das olerícolas, adotado na região da várzea, considerando ser mais fácil o manejo diário. O substrato utilizado pelas prateleiras vem de barco direto da várzea visto que o solo da terra firme é conhecido pela sua baixa fertilidade, segundo diversas entrevistas. Para cada canteiro de quarenta metros quadrados eram necessários 2500 quilos de substrato. Ao todo eram vinte e quatro canteiros na propriedade, sendo que por semana a propriedade produzia em média 300 quilos de alface, 90 quilos de couve, 20 quilos de coentro. A produção era em grande parte escoada para GRSA (Empresa de Soluções em Alimentação e em Serviços de Suporte), grande empresa de restaurante da região que atendia a uma mineradora; e uma pequena parte para um grande mercado local. Após cada ciclo de cultura era necessária a reposição da altura do substrato de cada prateleira em cerca de dois centímetros, pelas perdas de solo durante a irrigação manual. O produtor utilizava o cultivo protegido para a alface, a couve e o coentro.

Além da atividade principal, o proprietário estava investindo na fruticultura, ainda sem pretensões de comercialização, com o plantio de laranja, tangerina, coco, graviola e abacaxi.

A avaliação da propriedade utilizando a ferramenta SWOT é apresentada no quadro 1. 
Quadro 1: Análise SWOT de uma propriedade visitada na região de Terra firme:

\begin{tabular}{|c|c|c|}
\hline & Contribuem para a estratégia & Dificultam a estratégia \\
\hline \multirow{2}{*}{ 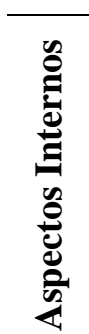 } & Forças & Fraquezas \\
\hline & $\begin{array}{l}\text { Conhecimento técnico; } \\
\text { Mão de obra suficiente; } \\
\text { Capacidade de fornecimento contínuo; } \\
\text { Diversidade de cultivos. }\end{array}$ & $\begin{array}{l}\text { Baixa fertilidade: necessidade de substrato; } \\
\text { Dependência de um comprador; } \\
\text { Sistema de irrigação com falhas. }\end{array}$ \\
\hline \multirow[b]{2}{*}{ 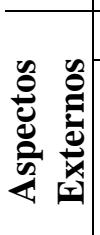 } & Oportunidades & Ameaças \\
\hline & $\begin{array}{l}\text { Boa aceitação do produto; } \\
\text { Facilidade para escoamento da produção; } \\
\text { Possibilidade de obtenção de crédito rural. }\end{array}$ & $\begin{array}{l}\text { Retorno financeiro: demora do pagamento; } \\
\text { Despesa com o cliente para cobrir } \\
\text { possíveis perdas do produto; } \\
\text { Dificuldade em encontrar novos mercados. }\end{array}$ \\
\hline
\end{tabular}

*Observação: O maior comprador desconta 5\% no valor do pagamento considerando perdas.

A outra propriedade visitada possuía 77 ha e havia sido comprada há 18 anos com a renda do extrativismo da castanha. A produção agrícola era para subsistência e comércio, sendo característica peculiar a muitas propriedades locais. Nesta propriedade a produção era oriunda do milho, feijão, arroz, melancia, mandioca, banana, além das hortaliças e alguns legumes do projeto PAIS (Produção Agroecológica Integrada e Sustentável). A comercialização era feita na feira da cidade, sendo o pagamento realizado no momento da entrega. O transporte era realizado através de um caminhão disponibilizado pela prefeitura que passava quase todos os dias. A falta de irrigação implicou em queda acentuada na produção de feijão no ano de 2012. Não eram utilizadas máquinas para plantio e as plantas daninhas retiradas, na maioria das vezes, eram deixadas como cobertura morta.

As sementes utilizadas eram fornecidas pela SEMAGRI e EMATER. Ainda era costume o uso de semente de paiol, ou seja, sementes guardadas de um ano para o outro. A queima era utilizada para algumas culturas. A mandioca era beneficiada na propriedade, mas a farinha produzida era direcionada apenas para o próprio consumo.

Além das culturas citadas, outra fonte de renda era a criação de galinha caipira, entretanto não havia o controle profilático de doenças.

A água utilizada vinha de um poço na comunidade e era bombeada para a caixa d'água na residência. Na produção agrícola não era utilizado nenhum sistema de irrigação, contando apenas com a chuva.

Para o gado na propriedade era feita uma parceria onde foram obtidas por empréstimo oito vacas e um filhote e todas as crias geradas a partir desses animais deviam ser divididas com o sócio. Na época da visita já havia cinco anos da parceria e 22 cabeças de gado dispostas em 10 hectares.

A avaliação da propriedade utilizando a ferramenta SWOT é apresentada no quadro 2. 
Quadro 2: Análise SWOT de outra propriedade visitada na região de Terra firme:

\begin{tabular}{c|l|l}
\cline { 2 - 3 } & \multicolumn{1}{|c|}{ Contribuem para a estratégia } & \multicolumn{1}{c}{ Forças } \\
\hline
\end{tabular}

* Observação: O projeto PAIS foi implantado na propriedade, mas o manejo tem sido inadequado sendo alegada como justificativa a falta de mão de obra disponível.

b) Várzea

Nas áreas de várzeas, por estarem localizadas em regiões muito próximas aos rios, a produção de hortaliças é feita em canteiros suspensos.

Na propriedade visitada, a estrutura de canteiros elevados para produção de hortaliças podia atingir a altura de 1,80 metros, sendo necessário o uso de passarelas. Como substrato, utilizava-se o solo argiloso e o esterco do gado da própria região da várzea. A maior parte do fornecimento das hortaliças ia para o distrito de Porto Trombetas, local abastecido havia 37 anos pelos produtores. Também era direcionada uma quantidade para a UAJV e mercados locais.

$\mathrm{Na}$ propriedade eram produzidos e colhidos com uma frequência de duas vezes por semana, em média, 190 quilos de alface, 60 quilos de couve, 13 quilos de cebolinha e 8 quilos de coentro. Os produtos fornecidos à GRSA eram pagos após sete semanas, sendo que cinco por cento do que era faturado pelo produtor era debitado do mesmo, para suprir as perdas. Segundo o produtor esta transação estava no contrato de fornecimento.

A propriedade possuía um motor gerador de energia elétrica a diesel que era ligado diariamente para fornecer luz para a residência, energia para o uso da bomba na irrigação e enchimento das caixas d'água.

A avaliação da propriedade utilizando a ferramenta SWOT é apresentada no quadro 3. 
Quadro 3: Análise SWOT da propriedade visitada na região Várzea:

\begin{tabular}{|c|c|c|}
\hline & Contribuem para a estratégia & Dificultam a estratégia \\
\hline \multirow[b]{2}{*}{ 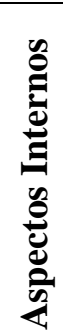 } & Forças & Fraquezas \\
\hline & $\begin{array}{l}\text { Experiência com cultivos suspensos; } \\
\text { Uso da plasticultura; } \\
\text { Fertilidade adequada do solo; } \\
\text { Boa qualidade do produto. }\end{array}$ & $\begin{array}{l}\text { Mão de obra insuficiente; } \\
\text { Necessidade de investimento em } \\
\text { irrigação; } \\
\text { Tempo despendido nas atividades. }\end{array}$ \\
\hline \multirow{2}{*}{ 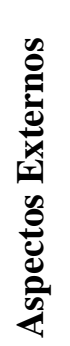 } & Oportunidades & Ameaças \\
\hline & $\begin{array}{l}\text { Possibilidade de obtenção de crédito } \\
\text { rural. }\end{array}$ & $\begin{array}{l}\text { Possibilidade de perdas com as } \\
\text { enchentes; } \\
\text { Ataque de animais nas enchentes. }\end{array}$ \\
\hline
\end{tabular}

c) Ribeirinha

Nesta região foram visitadas as comunidades da Cafelândia, Ascensão e uma propriedade específica por sua representatividade para a agricultura familiar do município.

À comunidade da Cafelândia pode-se chegar através de pequenas embarcações navegando pelo Lago Iripixi ou pelos ramais que são estradas vicinais, de terra batida, portanto, é de difícil acesso. Lá habitavam em torno de dez famílias que utilizavam um gerador a diesel para disporem apenas de três horas diárias de energia elétrica, das 19 às 22 horas. Essa energia era utilizada principalmente para as bombas hidráulicas encherem as caixas d'água e para recreação e distração, como assistir ao futebol e a novela. A comunidade alimentava-se da pesca e da agricultura, que ainda estava em desenvolvimento, principalmente com a chegada do projeto PAIS.

Em uma análise visual e pelos relatos dos comunitários, foi verificado que o solo da Cafelândia tinha as mesmas características do solo da região de Terra Firme: arenoso e de baixa fertilidade.

A produção agrícola da Cafelândia ainda não se destacava para o mercado local, caracterizando-se pelo plantio de mandioca para produzir a farinha, além de algumas espécies frutíferas como as bananeiras e abacaxis. As atividades agrícolas eram de caráter de subsistência. Porém, em 2011 a SEMAGRI levou o projeto PAIS para a Cafelândia, o que começou a mudar o cenário agrícola da comunidade. As famílias foram beneficiadas ganhando o suporte técnico e estrutural, como: caixas d'água, mangueiras, cercas, dentre outros materiais que completam o aparato do projeto, para implantar a horticultura. Portanto, foram construídas oito hortas em forma de mandala, com um galinheiro ao centro, utilizando como sistema de irrigação o gotejamento. 
No ano do desenvolvimento, cada família se responsabilizou por uma horta e os resultados foram considerados satisfatórios, destacando-se a produção de alface e cebolinha. $\mathrm{O}$ galinheiro ajuda a reforçar a alimentação com a produção de ovos.

Parte da produção era vendida na feira local de Oriximiná, porém não havia um controle da quantidade que era vendida ou consumida pelas famílias.

Outra comunidade visitada na região da Ribeirinha foi a de Ascensão, que se localiza às margens do lago Sapucuá.

A produção agrícola da Ascensão é focada no cultivo da mandioca com produtividade média de 13 toneladas de raiz por hectare, de acordo com a Emater local. Dez famílias da comunidade, que mantêm uma beneficiadora de mandioca, vêm sendo acompanhadas pela Emater, sendo capacitadas para aumentar a produtividade e qualidade da mandioca produzida. $\mathrm{O}$ projeto vem sendo conduzido com a Mineração Rio do Norte (MRN). Essa mesma empresa realiza na comunidade, como forma compensatória por exploração dos recursos naturais da região, o Projeto Pé-de-Pincha, que atua em defesa dos tracajás.

Ainda na região da Ribeirinha foi visitada outra propriedade que fazia parte do projeto PAIS, e que produzia principalmente: tomate, cebolinha, couve, alface, quiabo, alfavaca, jambú e pimenta. Existem algumas variedades de árvores frutíferas, como bananeiras, apenas para o consumo da família. Um gerador a diesel fornecia energia principalmente para as bombas que levavam água para as caixas d'água, incluindo a que abastecia o sistema de irrigação por gotejamento do projeto PAIS.

Havia a adoção da composteira para obtenção do substrato visando o preparo da horticultura e um viveiro para favorecer o desenvolvimento vegetal das mudas que eram plantadas na horta, dentre outras. Também havia uma pequena produção de mel de abelha Uruçu (Meliponascutellaris), que é feita de maneira simples e artesanal.

A avaliação das propriedades visitadas na comunidade de Ribeirinhas gerou a matriz SWOT apresentada no quadro 4.

A partir da avaliação das matrizes SWOT geradas pelas informações dos produtores locais e para um diagnóstico global da atividade por eles realizada foi montada uma matriz de análise estratégica. Para essa matriz (Quadro 5) foram adotadas como fraquezas e forças as características mais relevantes e comuns entre as propriedades por serem fatores limitantes ou fundamentais para sua melhoria, respectivamente. Na avaliação externa, utilizou-se o mesmo critério para definir quais as oportunidades e ameaças seriam destacadas na matriz. 
Quadro 4: Análise SWOT das comunidades em Ribeirinhas:

\begin{tabular}{|c|c|c|}
\hline & Contribuem para a estratégia & Dificultam a estratégia \\
\hline \multirow[b]{2}{*}{ 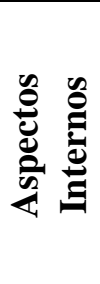 } & Forças & Fraquezas \\
\hline & $\begin{array}{l}\text { Produção de mel; } \\
\text { Produção de composto; } \\
\text { Produção de mudas; } \\
\text { Qualidade do produto; } \\
\text { Implantação do Projeto PAIS. }\end{array}$ & $\begin{array}{l}\text { Mão de obra insuficiente; } \\
\text { Baixa fertilidade do solo. }\end{array}$ \\
\hline \multirow{2}{*}{ 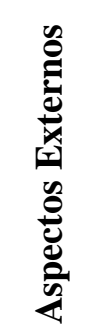 } & Oportunidades & Ameaças \\
\hline & $\begin{array}{l}\text { Capacitação técnica oferecida; } \\
\text { Possibilidade de obtenção de crédito } \\
\text { rural; } \\
\text { Possibilidade de agroindustrialização }\end{array}$ & $\begin{array}{l}\text { Dificuldade de acesso a energia elétrica; } \\
\text { Difícil acesso às propriedades, } \\
\text { complicando o escoamento da produção }\end{array}$ \\
\hline
\end{tabular}

Assim, no Quadro 5 as forças estão representadas pelas letras de A a E, indicando:

A - Oferta de produtos diversificados; B - Boa qualidade dos produtos oferecidos; C - Adoção do Projeto PAIS; D - Possibilidade de atividades se complementarem e, E - Perpetuação da atividade pelos filhos.

As fraquezas, por sua vez, estão representadas pelas letras de F a J, indicando:

F - Baixa Fertilidade do Solo; G - Mão de obra insuficiente; H - Capacitação técnica insuficiente dos produtores rurais; I - Tempo elevado gasto nas atividades; J - Necessidade de alguns equipamentos, como por exemplo, para irrigação.

As oportunidades estão representadas pelas letras de $\mathrm{K}$ a $\mathrm{P}$, indicando:

K - Assistência técnica disponível: EMATER, UFF, Secretaria Municipal; L - Há demanda no mercado pelos produtos agrícolas; M - Possibilidade de capacitação e treinamento por instituições presentes no município; N - Possibilidade de obtenção de crédito rural pelo PRONAF; O - Possibilidade de organização em associações; P - Localização estratégica: turismo rural, extração sustentável, dentre outras.

As ameaças estão representadas na Quadro 5 pelas letras de Q a U, indicando:

Q - Retorno do Investimento: demora do pagamento pelos clientes; $\mathbf{R}$ - Restrições impostas pela legislação ambiental, $\mathbf{S}$ - Descontos impostos por clientes no valor recebido por produtos, $\mathbf{T}$ Fatores climáticos afetam a produção; $\mathbf{U}$ - Dificuldades no escoamento da produção.

De acordo com o confronto entre as fraquezas e as forças com as oportunidades e ameaças foi estabelecida uma pontuação considerando como critérios: pouco significativa (1), significativa (2) e muito significativa (3). Buscou-se fazer o julgamento e atribuição dos valores conciliando os dados obtidos na entrevista com a observação in loco. A soma da pontuação obtida nos cruzamentos entre forças e oportunidades definiu o potencial ofensivo; entre forças e 
ameaças definiu o potencial defensivo; entre fraquezas e oportunidades definiu a debilidade ofensiva e finalmente, entre fraquezas e ameaças definiu as vulnerabilidades (Quadro 5).

Assim, para traçar o diagnóstico estratégico considerou-se que em se tratando de agricultores familiares com atividades similares, dentre elas a olericultura, poder-se-ia adotar a mesma visão para todas as propriedades que é ser um empreendimento rural produtivo, com sustentabilidade econômica e ambiental, garantindo a perpetuação das atividades na família ao longo dos anos; tendo como missão oferecer produtos agrícolas de qualidade atendendo à necessidade do mercado sem agredir o meio ambiente. Procurou-se na correlação entre as linhas e colunas da matriz estratégica manter como foco o alcance da visão adotada, o que significaria o sucesso do empreendimento, pautado na definição de sucesso adotada por Kerzner (2006), ou seja, concretizar os objetivos atendendo às condicionantes de tempo alocado, custos orçados, desempenho desejado em nível técnico ou de metas e padrões de qualidade definidos pelos clientes.

Quadro 5: Análise SWOT das Propriedades de agricultores familiares visitadas em Oriximiná.

\begin{tabular}{|c|c|c|c|c|c|c|c|c|c|c|c|c|c|c|c|}
\hline \multirow{2}{*}{\multicolumn{2}{|c|}{\begin{tabular}{l}
\multicolumn{1}{r}{$\mathbf{P}$} \\
1. PS \\
2. S \\
3. MS
\end{tabular}}} & \multicolumn{7}{|c|}{ OPORTUNIDADES } & \multicolumn{6}{|c|}{ AMEAÇAS } & \multirow[b]{2}{*}{$\mathbf{T}$} \\
\hline & & $\mathbf{K}$ & $\mathbf{L}$ & $\mathbf{M}$ & $\mathbf{N}$ & $\mathbf{O}$ & $\mathbf{P}$ & $\mathbf{S}$ & $\mathbf{Q}$ & $\mathbf{R}$ & $\mathbf{S}$ & $\mathbf{T}$ & $\mathbf{U}$ & $\mathbf{S}$ & \\
\hline \multirow{7}{*}{$\begin{array}{l}\sum_{0}^{\infty} \\
\underbrace{n}_{0}\end{array}$} & $\mathbf{A}$ & 3 & 3 & 3 & 2 & 3 & 3 & 17 & 3 & 1 & 2 & 2 & 1 & 9 & 26 \\
\hline & B & 2 & 3 & 2 & 3 & 2 & 3 & 15 & 1 & 2 & 3 & 1 & 1 & 8 & 23 \\
\hline & $\bar{C}$ & 3 & 3 & 3 & 3 & 3 & 2 & 17 & 1 & 3 & 1 & 2 & 1 & 8 & 25 \\
\hline & D & 3 & 1 & 3 & 1 & 1 & 2 & 11 & 1 & 1 & 1 & 1 & 1 & 5 & 16 \\
\hline & $\mathbf{E}$ & 1 & 1 & 3 & 1 & 1 & 2 & 9 & 1 & 2 & 1 & 1 & 1 & 6 & 15 \\
\hline & St & 12 & 11 & 14 & 10 & 10 & 12 & 69 & 7 & 9 & 8 & 7 & 5 & 36 & \\
\hline & & \multicolumn{6}{|c|}{ Potencial Ofensivo } & 69 & \multicolumn{5}{|c|}{ Potencial Defensivo } & 36 & \\
\hline \multirow{8}{*}{$\begin{array}{l}\frac{\pi}{3} \\
\frac{1}{5} \\
\frac{0}{2} \\
\frac{\pi}{2}\end{array}$} & $\mathbf{F}$ & 1 & 3 & 1 & 2 & 1 & 1 & 9 & 3 & 3 & 3 & 3 & 1 & 13 & 22 \\
\hline & G & 3 & 3 & 3 & 1 & 1 & 2 & 13 & 1 & 1 & 3 & 2 & 1 & 8 & 21 \\
\hline & $\mathbf{H}$ & 3 & 3 & 3 & 3 & 1 & 2 & 15 & 1 & 3 & 3 & 3 & 1 & 11 & 26 \\
\hline & I & 3 & 3 & 3 & 1 & 1 & 2 & 13 & 1 & 1 & 1 & 1 & 2 & 6 & 19 \\
\hline & $\mathbf{J}$ & 1 & 3 & 1 & 2 & 1 & 2 & 10 & 3 & 3 & 3 & 3 & 1 & 13 & 23 \\
\hline & $\mathrm{St}$ & 11 & 15 & 11 & 9 & 5 & 9 & 60 & 9 & 11 & 13 & 12 & 6 & 51 & \\
\hline & Total & 23 & 26 & 25 & 19 & 15 & 21 & & 16 & 20 & 21 & 19 & 11 & & \\
\hline & & \multicolumn{6}{|c|}{ Debilidade Ofensiva } & 0 & \multicolumn{5}{|c|}{ Vulnerabilidade } & 51 & \\
\hline
\end{tabular}

Legenda: PS - pouco significativa, $\mathrm{S}$ - significativa; MS - muito significativa; $\mathrm{St}$ - subtotal.

O potencial ofensivo foi definido pelo confronto entre as forças e as oportunidades encontradas, apresentando-se promissor visto que dos 90 pontos possíveis de serem alcançados foi encontrado um valor em torno de $77 \%$ do potencial máximo. Destaca-se a oferta de produtos diversificados e a adoção do projeto PAIS como sendo as forças mais importantes para o aproveitamento de todas as oportunidades elencadas. Deve-se ressaltar que a Produção Agroecológica Integrada Sustentável é uma tecnologia social que se adéqua bem ao perfil do 
agricultor familiar aliado à sustentabilidade, visto que, como bem apontado por Otterloo et al. (2009) e Pena (2010) a tecnologia PAIS está alicerçada no modelo agroecológico, permitindo o consórcio e interação de atividades, priorizando o uso de insumos da propriedade, buscando empregar variedades melhoradas pelos próprios agricultores e adaptadas às condições ambientais e de solo de cada local, incentivando o associativismo e apontando novos canais de comercialização do excedente da produção. Entretanto, foi verificado em campo que o uso intensivo de mão de obra é uma das dificuldades para o bom desempenho desta tecnologia. A diversificação de produtos agrícolas também é apontada como determinante para o sucesso da agricultura familiar por outros autores, por diversos fatores, tais como: novas opções de renda, por não exigir grandes investimentos, por aproximar a atividade do que ocorre na natureza (HAAS, 2008; VALANDRO et al, 2011).

$\mathrm{Na}$ matriz de diagnóstico estratégico também foi verificado que as forças identificadas podem ser insuficientes para reduzir as fragilidades externas a que os sistemas rurais estão expostos, não sendo capazes de se contraporem às ameaças, o que está indicado por um potencial defensivo bem aquém do desejado, correspondendo a apenas $48 \%$ do máximo possível. Porém, a diversificação dos produtos é uma força que pode reduzir as ameaças. Ressalta-se assim a importância dos agricultores familiares investirem em diferentes atividades rurais para reduzirem os riscos a que estão expostos seja pela oscilação de preços ou intempéries, por exemplo, como ocorre nas Várzeas.

Merece atenção a legislação ambiental posta como ameaça. Ahrens, Paiva e Wendling (2007) destacam a vastidão do arcabouço legal ambiental, disperso em diversos diplomas legais, relacionado à ocupação, uso e proteção dos espaços internos de uma propriedade rural, bem como dos recursos naturais nela existentes ou que deveriam existir. Verificou-se em campo a dificuldade de muitos agricultores familiares em compreender várias questões relativas à legislação ambiental, obedecendo-a por imposição sem entender o motivo de sua aplicação.

Binsztok (2008) analisando as transformações ocorridas na agricultura familiar na Amazônia nesta última década, centrando-se em Rondônia, pontuou a dificuldade da aplicação da legislação ambiental devido à sua fragmentação, apesar da ampla divulgação e debate, e sugeriu que esta fosse adequada às necessidades específicas dos agricultores familiares, privilegiando particularmente a reposição florestal e a recuperação das áreas de preservação permanente, visto que é possível compatibilizar a preservação ambiental com as práticas agrícolas.

$\mathrm{Na}$ análise da debilidade ofensiva do sistema verificou-se que esta também merece atenção visto que as ameaças identificadas podem dificultar o aproveitamento das oportunidades. A ação da assistência técnica é um ponto vital para auxiliar na redução dessa debilidade ofensiva visto que a maior fraqueza está correlacionada à necessidade de capacitação técnica dos produtores rurais, o que poderia compensar ou reduzir outras fraquezas, como por 
exemplo, auxiliando na adoção de técnicas e equipamentos que reduzissem o tempo operacional e a mão de obra necessária nas atividades, bem como em ações que pudessem aumentar a fertilidade do solo, tais como coleta e análise de solo, informação e aplicação da compostagem e outros biofertilizantes. Quando os produtores rurais conhecem e utilizam as técnicas mais adequadas, encaminham-se rumo à sustentabilidade do sistema, diversificando a produção, mantendo a qualidade e o controle que reduzem pragas e doenças, diminuindo o aporte de insumos externos pela reutilização dos resíduos na propriedade. A assistência e capacitação técnica são possíveis e ocorrem no município por várias entidades presentes, denotando que falta apenas uma maior articulação para ampliar sua ação de forma mais efetiva.

Deve-se ressaltar que em trabalho realizado por Simoni et al. (2012) analisando a estrutura político-institucional relacionada a gestão do uso da terra e produção familiar em dois municípios do Baixo Amazonas (Santarém e Monte Alegre), um dos pontos levantados foi a importância da interiorização das universidades públicas como uma oportunidade para estabelecer bases científicas e técnicas que pudessem auxiliar a entender e atuar na realidade regional, inter-relacionando com os órgãos de gestão e também com os produtores locais, permitindo a criação de redes de pesquisas e fortalecendo as já existentes, de forma a auxiliar no compartilhamento de dados sobre vulnerabilidade e adaptação, respeitando as especificidades regionais e científicas. Em Oriximiná verificou-se que há essa integração entre a UAJV, a EMATER e a Secretaria de agricultura, atendendo aos produtores rurais. Entretanto, há a necessidade de tornar as ações mais efetivas, indo ao encontro das necessidades apontadas pelos produtores rurais.

Deve-se destacar que a oportunidade mais expressiva indicada pela análise estratégica é a demanda apresentada pelo mercado aos produtos agrícolas o que sugere que os investimentos em capacitação poderão aumentar a produtividade e melhorar, portanto o rendimento dos agricultores familiares.

Apesar do associativismo ser uma ferramenta importante para fortalecer os empreendimentos de agricultores familiares, seja na redução de custos para compra de insumos, na busca da agroindustrialização ou na organização para venda de produtos, dentre outras oportunidades, seu impacto positivo ainda não é notado pelos produtores rurais. Verifica-se que há muita resistência por parte destes em formar associações, o que também foi apontado no trabalho de Ferreira e Alencar (2007).

$\mathrm{Na}$ análise da vulnerabilidade, pelo confronto dos pontos fracos com as ameaças, verificou-se que as fraquezas dos sistemas rurais que os tornam mais vulneráveis aos impactos das ameaças, são a baixa fertilidade do solo e a ausência de técnicas e equipamentos. Nota-se também aqui a necessidade de aumentar o contato entre a assistência técnica e os produtores rurais, seja pela orientação direta em campo ou por diferentes formas de capacitação que orientem quanto às técnicas de manejo adequadas, utilização de equipamentos e até mesmo a 
agroindustrialização dos produtos o que reduziria os impactos causados pela dificuldade de escoamento da produção, visto que aumentaria a vida útil do produto ao mesmo tempo em que agregaria valor. A necessidade de capacitação dos produtores para reduzir ameaças também foi apontada no trabalho de Ferreira e Alencar (2007) em que entrevistados demonstraram preocupação com a conservação do solo para manutenção da fertilidade e apontaram além do baixo nível de escolaridade dos produtores, a falha na disseminação de informações sobre o manejo do solo atribuída aos órgãos governamentais ligados à agropecuária.

A capacitação também pode auxiliar no empoderamento dos produtores rurais para que possam negociar formas mais justas de comércio de seus produtos o que reduziria a ameaça de maior impacto que são os descontos recebidos no valor do produto. Visando a sustentabilidade da atividade, poderia ser negociada a transformação do valor descontado em investimento visando a redução de perdas dos produtos agrícolas.

No trabalho de Ferreira e Alencar ressaltou-se que a falta de máquinas e equipamentos necessários para aproveitar potencialidades locais era devida à ausência de recursos financeiros dos produtores familiares para aquisição, sendo sugeridas políticas de crédito para financiamento com juros baixos. Apesar do Programa PRONAF ir ao encontro dessa aspiração é importante o planejamento da atividade de forma a não causar o endividamento do produtor rural.

Deve-se ressaltar ainda que há a possibilidade real de que os filhos dos agricultores das propriedades rurais de Oriximiná permaneçam em campo. Apesar de esta força ter se mostrado como a menos expressiva, em longo prazo é uma das mais significativas caso estratégias sejam adotadas para potencializar as forças e reduzir as fraquezas, levando assim à perpetuação da atividade, aproveitando as oportunidades e reduzindo as ameaças.

\section{Conclusões}

Nas propriedades rurais avaliadas em Oriximiná verificou-se que há um potencial ofensivo promissor, destacando-se a oferta de produtos diversificados, com ampla colaboração da olericultura, e a adoção da tecnologia PAIS (Produção Agroecológica Integrada Sustentável). Entretanto as forças devem ser melhor trabalhadas para reduzir ameaças, tais como a não adequação à legislação ambiental. Deve-se ressaltar que a ação da assistência técnica, seja por orientação ou capacitação mostrou-se como um ponto vital para auxiliar na redução da debilidade ofensiva e que apesar dela ocorrer no município há a necessidade de uma maior articulação para ampliar sua ação de forma mais efetiva. Isto também poderia auxiliar a reduzir a vulnerabilidade dos sistemas agrícolas a algumas fraquezas, como a baixa fertilidade do solo e a ausência de técnicas e equipamentos. 
Portanto, o diagnóstico a partir das matrizes SWOT e da matriz estratégica mostrou-se como uma ferramenta adequada e útil para caracterização das propriedades rurais individualmente e em uma análise global, visto que auxiliou na identificação do potencial ofensivo, indicando as forças a serem trabalhadas para que as oportunidades disponíveis pudessem ser alcançadas, ao mesmo tempo em que mostrou a vulnerabilidade do sistema apontando para as fraquezas que deviam ser reduzidas ou eliminadas de forma a minimizar as ameaças a que a atividade estava exposta e que poderiam levá-la a sucumbir. Tais informações podem aumentar a produtividade de propriedades agrícolas sem haver a expansão territorial, auxiliando também na condução para a sustentabilidade da atividade.

\section{Agradecimentos:}

Pró-reitoria de extensão (Proex-UFF), Prof. James Hall (UFF), Secretaria de Agricultura de Oriximiná, UAJV, EMATER e ao Prof. Eduardo Salgado (UNIFAL).

\section{Referências}

AB'SÁBER, A.N. Do Código Florestal para o Código da Biodiversidade. Biota Neotrop. v.10, n. 4, p. 331-36, 2010.

AHRENS, S.; PAIVA, A. V. M; WENDLING, J. L. G. Legislação pertinente à gestão ambiental na propriedade imóvel agrária. In: GEBLER, L.; PALHARES, J. C. P. (Org.). Gestão Ambiental na Agropecuária. Brasília: Embrapa Informação Tecnológica, 2007, p.62-85.

ALMEIDA, A. C. S. et. al. Caracterização de produtores e propriedades rurais em três municípios do estado de Pernambuco. Caatinga. v.19, n.4, p.323-332, 2006.

ARRAES, R. A.; MARIANO, F. Z.; SIMONASSI, A. G. Causas do Desmatamento no Brasil e seu ordenamento no contexto mundial. RESR. v. 50, n 1, p. 119-140, 2012.

BARRETO, H. F. M. et. al. Impactos ambientais do manejo agroecológico da caatinga no Rio Grande do Norte. Pesq. agropec. bras. v.45, n.10, p.1073-1081, 2010.

BINSZTOK, J. Transformações sócio-espaciais da agricultura familiar na Amazônia. Scripta Nova. v. 12, n. 270, p. 78, 2008.

BRASIL. Lei Federal $n^{\circ}$. 11326, de 24 de julho de 2006. Estabelece as diretrizes para a formulação da Política Nacional da Agricultura Familiar e Empreendimentos Familiares Rurais. Diário Oficial [da] República Federativa do Brasil, Brasília, DF, 25 jul. 2006. Disponível em: $<$ http://legis.senado.leg.br/legislacao/ListaTextoIntegral.action?id=233477\&norma=254527>. Acesso em: 22 abr. 2013.

BRASIL. Lei Federal ñ. 12.651, de 25 de maio de 2012. Dispõe sobre a proteção da vegetação nativa; altera as Leis $\mathrm{n}^{\text {os }} 6.938$, de 31 de agosto de 1981, 9.393, de 19 de dezembro de 1996, e 11.428, de 22 de dezembro de 2006; revoga as Leis $\mathrm{n}^{\text {os }} 4.771$, de 15 de setembro de 1965, e 7.754, de 14 de abril de 1989, e a Medida Provisória n ${ }^{0}$ 2.166-67, de 24 de agosto de 2001; e dá outras providências. Diário Oficial [da] República Federativa do Brasil, Brasília, DF, 28 mai. 2012. Disponível em: <http://www.planalto.gov.br/ccivil_03/_Ato2011-

2014/2012/Lei/L12651.htm>. Acesso em: 24 abr. 2013.

BRASIL. Ministério do Desenvolvimento Agrário. Política Nacional de Assistência Técnica e Extensão Rural (PNATER). Disponível em: 
http://comunidades.mda.gov.br/portal/saf/programas/assistenciatecnica/2522569. Acesso em: 24 abr. 2013.

BRASIL. Ministério do Desenvolvimento Agrário. Um novo Brasil rural. Ministério do Desenvolvimento Agrário, 2003-2010. Brasília: MDA, 2010. 127 p.

CALDEIRA, D. R. M. et al. Identificação, catalogação e valoração de espécies arbóreas em reserva legal de Amazônia Legal para usos múltiplos. In: I CONGRESSO BRASILEIRO DE GESTÃO AMBIENTAL. Bauru: 2010.

FERREIRA, F. P. M. Desenvolvimento regional e planejamento estratégico: aplicações para o sudeste do Tocantins. Revista Gestão e Planejamento, Salvador, v. 12, n. 2, p. 267-282, 2011. FERREIRA, P. A.; ALENCAR, E. Potencialidades e limitações da agricultura familiar no sul de Minas Gerais: um diagnóstico fundamentado na abordagem interpretativa. Organizações Rurais e Agroindustriais, Lavras, v. 9, n. 3, p. 421-436, 2007.

GHEMAWAT, P. A Estratégia e o Cenário dos Negócios: Textos e Casos. Tradução de Nivaldo Montingelli Jr. 1. ed. Porto Alegre: Bookman, 2000, p. 19.

GIL, A. C. Métodos e técnicas de pesquisa social. 6. ed. São Paulo: Atlas, 2008.

GLIESSMAN, S. R. Agroecologia: processos ecológicos em agricultura sustentável. Porto Alegre: Editora da UFRGS, 2005. 653 p.

HAAS, J. M. Diversificação de produção no meio rural como estratégia de sobrevivência: um estudo de caso da região noroeste do Rio Grande do Sul. IV Encontro Nacional da Anppas, 4 a 6 de junho de 2008, Brasília - DF.

KERZNER, H. Gestão de projeto: as melhores práticas. Tradução de Lene Belon Ribeiro. 2. ed. Porto Alegre: Bookman, 2006.

INSTITUTO NACIONAL DE PESQUISAS ESPACIAIS - INPE. INPE estima $4.656 \mathrm{~km}^{2}$ desmatados na Amazônia em 2012. Disponível em:

$<$ http://www.inpe.br/noticias/noticia.php?Cod Noticia=3155>. Acesso em: 13 fev. 2013. INSTITUTO NACIONAL DE COLONIZAÇÃO E REFORMA AGRÁRIA - INCRA. Instrução especial. INCRA n ${ }^{\circ} 20$, de 28 de mai. 1980.

INSTITUTO BRASILEIRO DE GEOGRAFIA E ESTATÍSTICA - IBGE. Informações estatísticas sobre o município de Oriximiná - Pará. Censo Demográfico de 2010. Disponível em: http://www.ibge.gov.br/cidadesat/xtras/perfil.php?codmun=150530. Acesso em: 13 de out. 2012.

IRIAS, L. J. M. et al. Sistema de Avaliação de Impacto Ambiental de Inovações Tecnológicas nos Segmentos Agropecuário, Produção Animal e Agroindústria. Circular Técnica 5. Jaguariúna: 2004. 8 p.

MACEDO, D.; BORTOT, I. J.Agricultura familiar pode ajudar no combate à inflação. Agência Brasil, junho de 2011. Disponível em: <http://agenciabrasil.ebc.com.br/noticia/2011-0604/agricultura-familiar-pode-ajudar-no-combate-inflacao >. Acesso em: 14 de fev. 2013. MARCELINO, G. F. Gestão Estratégica em Universidades: o caso da Faculdade de Estudos Sociais Aplicados da Universidade de Brasília (FA/UnB). XXVII ENANPAD. 2003. (Encontro), $16 \mathrm{p}$.

METZGER, J. P. O código florestal tem base científica? Natureza e Conservação. v.8, n.1, p.92-99, 2010.

MINISTÉRIO DA SAÚDE, UNIVERSIDADE FEDERAL DO PARÁ, Diagnóstico local do município de Oriximiná- PA. Belém, 2009.

MIRANDA, A. EMATER capacita horticultores de Oriximiná. EMATER - Empresa de Assistência Técnica e Extensão Rural: Pará, regional de Santarém. Publicado em 09 de jul. de 2012. Disponível em: <http://www.emater.pa.gov.br/noticia/270> . Consulta feita em dez. 2012. NASCIMENTO, F. N. et al. Planejamento estratégico em uma pequena propriedade produtora de leite. Porto Alegre: 26 a 30 de julho de 2009, Sociedade Brasileira de Economia, Administração e Sociologia Rural. 13 p. 
NERI, M. C.; MELO, L. C. C.; MONTE, S. R. S. Superação da pobreza e a nova classe média no campo. Brasília: Ministério do Desenvolvimento Agrário, Fundação Getúlio Vargas, 313 p., 2012.

OLIVEIRA, T. M. V. Amostragem não Probabilística: Adequação de Situações para uso e Limitações de amostras por Conveniência, Julgamento e Quotas. Administração on line: prática, pesquisa, ensino, v. 2, n. 3, jul./ago./set. 2001. Consulta feita em dezembro de 2012. Disponível em:<http://www.fecap.br/adm_online/art23/tania2.htm>

OTTERLOO, A., et al, Tecnologias Sociais: Caminhos para a sustentabilidade. Brasília/DF: s.n, 2009. $278 \mathrm{p}$.

PADILHA; A. C. M. et al. O desenvolvimento do diagnóstico estratégico em propriedades rurais do agronegócio: análise ambiental em uma propriedade rural familiar. INGEPRO Inovação, Gestão e Produção. v.2, n. 6, 57-68 p., 2010.

PENA, J. O. O papel da tecnologia social para o desenvolvimento sustentável. In: Tecnologia Social e Desenvolvimento Sustentável: Contribuições da RTS para a formulação de uma Política de Estado de Ciência, Tecnologia e Inovação. Brasília: Secretaria Executiva da Rede de Tecnologia Social (RTS), p. 43-46, 2010.

PINTO, L. F. G.; CRESTANA, S. Características edafoclimáticas e informações socioeconômicas no diagnóstico de agroecossistemas da região de São Carlos, SP. Pesq. agropec. bras., Brasília, v. 36, n. 11, p. 1325-1329, 2001.

RODRIGUES, G. S. et al. Sistema de Avaliação de Impacto Social da Inovação Tecnológica Agropecuária (Ambietc-Social). Boletim de Pesquisa e Desenvolvimento. Jaguariúna: Embrapa Meio Ambiente, 31 p., 2005.

SIMONI et al. Instituições e políticas públicas em territórios da Amazônia: desafios para a capacidade adaptativa e redução de vulnerabilidades. VI ENCONTRO NACIONAL DA ANPPAS. Belém: 20 p., 2012.

SOUZA, P. J. O. P. (2010). Avanço da fronteira agrícola na Amazônia: impactos ambientais sob o ponto de vista climático. Folha Socioambiental, Ano 1, n. 2, p. 1-7, 2010.

VALANDRO, K.; PERONDI, M. A.; KIYOTA, N; VILLWOCK, A. N. P.; SIMONETTI, D. O impacto das estratégicas de diversificação nas rendas dos agricultores: um estudo numa comunidade rural. Synergismus scyentifica. UTFPR, Pato Branco, (06) 1, 2011.

YIN, R. K. Estudo de caso: planejamento e métodos. Tradução de Daniel Grassi. 2.ed. Porto Alegre : Bookman, 205 p., 2001. 